\title{
IFC-Based Computational Support Tool for Managing and Using Design Planning Information: Case Application and Evaluation
}

\section{Jongcheol Seo and Inhan Kim}

Research Professor, Department of Architecture, Kyung Hee University, Korea

Professor, Department of Architecture, Kyung Hee University, Korea

\begin{abstract}
Planning information generated during initial architectural design phases significantly influences subsequent phases, and is implemented into architectural design models during the design process. However, failures to manage and use planning information in Korean design offices remain common. Current design tools that incorporate planning information also do not address the issue of interoperability during the life cycles of buildings. To address these problems, the Industry Foundation Classes (IFC) extension model was developed to accommodate the need to manage and use planning information for cooperation between design offices carrying out multidisciplinary tasks. This paper introduces a purpose-built software tool that implements the IFC model and demonstrates the efficiency of the proposed method with the software tool.
\end{abstract}

Keywords : Design Model, Planning Information, Industry Foundation Classes (IFC), IFC Extension Model, Pm-DPIMS

\section{INTRODUCTION}

The design process in architecture includes sequential workflows such as planning, feasibility study, schematic design, design development, and construction document phase. The design process depends on design information generated through cooperation after the initial phases of design. As design information generated during the initial phases of a project is interpreted during later phases, errors committed during the initial phase are constantly discovered. Consequently, incorrect initial design information may constitute a significant problem that reduces the quality of design products generated during the life cycle of buildings; in particular, planning information such as design objectives, requirements, and constraint conditions has a significant influence on subsequent phases of the design process. Therefore,

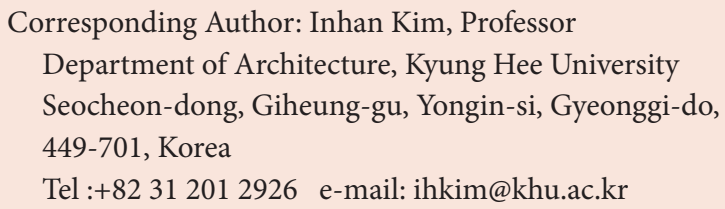

This work was supported by a post-doctoral fellow ship grant from the Kyung Hee University in 2011 (KHU-20110220)

This is an Open Access article distributed under the terms of the Creative Commons Attribution Non-Commercial License (http://creativecommons. org/licenses/by-nc/3.0/) which permits unrestricted non-commercial use, distribution, and reproduction in any medium, provided the original work is properly cited. it is important that design projects allow for collaboration and adjustment by participants in their initial phases. Moreover, the planning information should be continuously shared, managed, and used during the design process. However, general projects in design offices remain time-consuming and laborious. Problems that arise in design projects include the following

- Arbitrary or authoritative behavior of team leaders may make it difficult to communicate information among participants and result in errors and low design quality (Shin et al., 2006).

- Inadequate planning information cannot be used during the design process because it takes significant amounts of time and labor to modify design errors (Hitchcock, 1996).

- Work efficiency decreases because of incompatibilities among heterogeneous file formats generated by various design tools and a lack of interoperability caused by the manual re-inputting of data drawn from combinations of paper documents and electronic sources (Gallaher et al., 2004).

- The failure to manage planning items that are formulated during initial phases makes it more difficult for participants to collect, analyze, and define planning information derived from documents such as drawings, charts, spreadsheets, and guidelines (Hong and Song, 2002; Choi et al., 2006).

Regarding these issues, previous studies (Hitchcock, 1996; Cooper, 2005; Boddy, 2007; Ozkaya, 2007) proposed a variety of systematic methods and their solutions, eliminating many of the customary practices performed informally during the design process. Application tools such as EcoProp" (VTT, 2009), Design Intent Tool' (LBNL, 2009), Facility Composer ${ }^{\circ}$ (USACE, 2010), 
and Affinity (Trelligence, 2010) were developed for academic or commercial purposes to support the management and use of planning information such as objectives, requirements, and constraint conditions during the schematic design phase. In particular, the native file format generated by the Affinity tool can be used in design modeling tools such as Revit and ArchiCAD ${ }^{\circ}$. However, the tool cannot support the continuous management and use of planning information generated during the design process because it only supports the process until the schematic design phase, and can then be used only with particular modeling tools. This limitation may be restrictive, since planning information must be implemented into a building model through cooperation and adjustment among participants during the design process. It also does not address the need to share and exchange design information (i.e., planning information and design model). (See Ref. Seo and Kim, 2009, for a review of previous researches and application tools.)

To address interoperability issue, a standardized information format and method should be applied to improve information sharing with a relation between design modeling and planning tools. In this context, international research and development efforts have been conducted by BuildingSMART International (2010) (previously called the International Alliance for Interoperability). The BuildingSMART International developed the Industry Foundation Classes (IFC) standard (BuildingSMART, 2011), which is recognized as a unique solution supporting the exchange and sharing of information among architecture, engineering, and construction (AEC) applications. However, the capture of planning information in IFC remains a significant issue for IFC extensions, because IFC specifications do not support formal, explicit semantic descriptions of design information. For this reason, Seo and Kim (2009) developed the IFC extension model, which enables the capture of planning information and the relation of planning information to spatial structure elements in IFC. However, the research focused on developing and verifying IFC data models rather than using the method in practice.

This paper describes a proposed method managing and using planning information in IFC, and discusses its application and evaluation. The application and evaluation were conducted by participants at three design offices. In this paper, Section 2 briefly describes how a Product Model-based Design Planning Information Management System (Pm-DPIMS) is implemented and used as a prototype tool. Section 3 proposes a method for the management and use of planning information using the PmDPIMS in the design process. Finally, Section 4 demonstrates that the proposed method can be used to solve actual problems as mentioned above.

\section{PM-DPIMS OVERVIEW}

\subsection{Implementation}

As mentioned in the Introduction, problems arising in design practices result from failures to manage and use design information. The Pm-DPIMS is a purpose-built prototype tool that was developed to manage planning information and design models in an IFC standard environment. The Pm-DPIMS supports an integrated management and use of a design model with planning information to share and exchange design information among design modeling tools when IFC is applied. It is unique in that it uses IFC according to an explicit method that is explained in Section 3.

Pm-DPIMS is mainly composed of input, link, IFC conversion, and Revit add-on module, as shown in Figure 1. The IFC conversion module was implemented using the input and output modules provided by the $\mathrm{EDM}^{\circ}$ tool. The other modules (except for the Revit add-on) were implemented using Microsoft's Visual Basic language. The Revit add-on module was implemented using the Revit 2008 Software Developer Kit (SDK) and Visual Basic.Net ${ }^{\circ}$ language, and it was designed to support the tracing and viewing of semantic descriptions existing within an IFC design model.

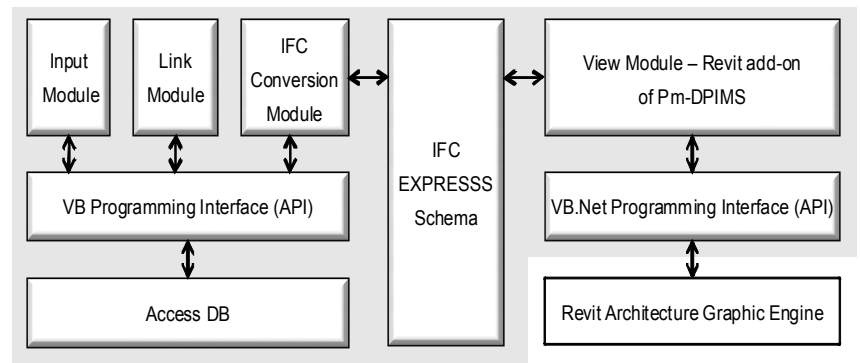

Figure 1. Pm-DPIMS configuration

\subsection{Main Functions}

\subsubsection{Capture of Planning Information}

This section describes how planning information was generated and mapped in the Pm-DPIMS. The planning items were first reviewed and defined by the participants in charge from five design offices in terms of practical use in the apartment building design, with commonly applicable and user-defined form (See Ref. Seo and Kim, 2009, for more detail information.).

The planning information was first generated by participants in charge of apartment building design projects, as shown in Figure 2. The Pm-DPIMS provides a template mdb file, which includes the planning items required to input the planning information in the design for apartment buildings. The information inputted into the planning items of the template is saved into an mdb list and generated as an mdb file type. All planning information for project and spatial structure elements (a) is composed of values inputted into the planning items. In addition, each spatial structure element can be added and deleted according to the hierarchical structure of the space. In terms of the IFC standard, each planning item is connected to the project and spatial structure elements and mapped into existing objects, Psets, properties, and IFC extension model (newly defined Psets and their properties) (Seo and Kim, 2009). For instance, the project window (b) is composed of tabs such as overview, conformity, cost, energy, and requirements. These tabs are the IFC Psets. The general tab includes the general characteristics of a project as a sub-tab in the overview tab; planning items such as project and code name (IfcProject), contract and delivery dates (IfcScheduleTimeControl), and approval date and state (IfcApproval), are defined (among others) as existing IFC objects. In other cases, the window (c) is composed of tabs such as overview, service, safety, external view and finishing, and requirements. The planning items shown in the overview tab 


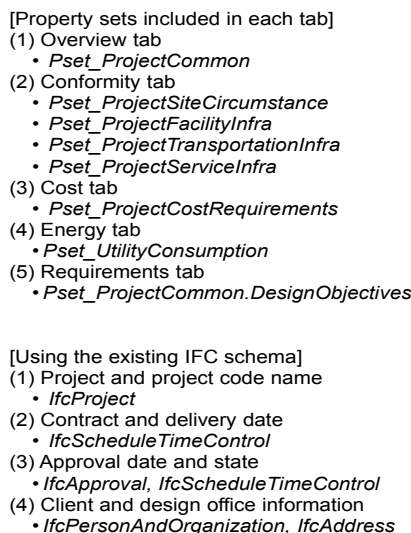

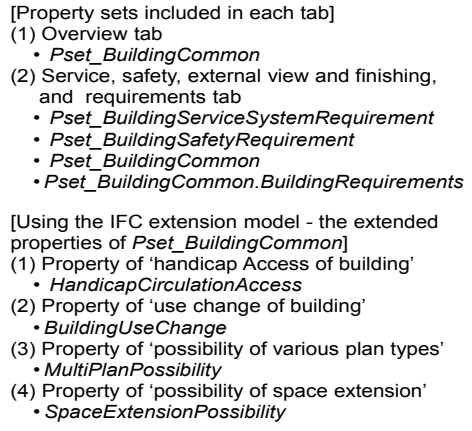

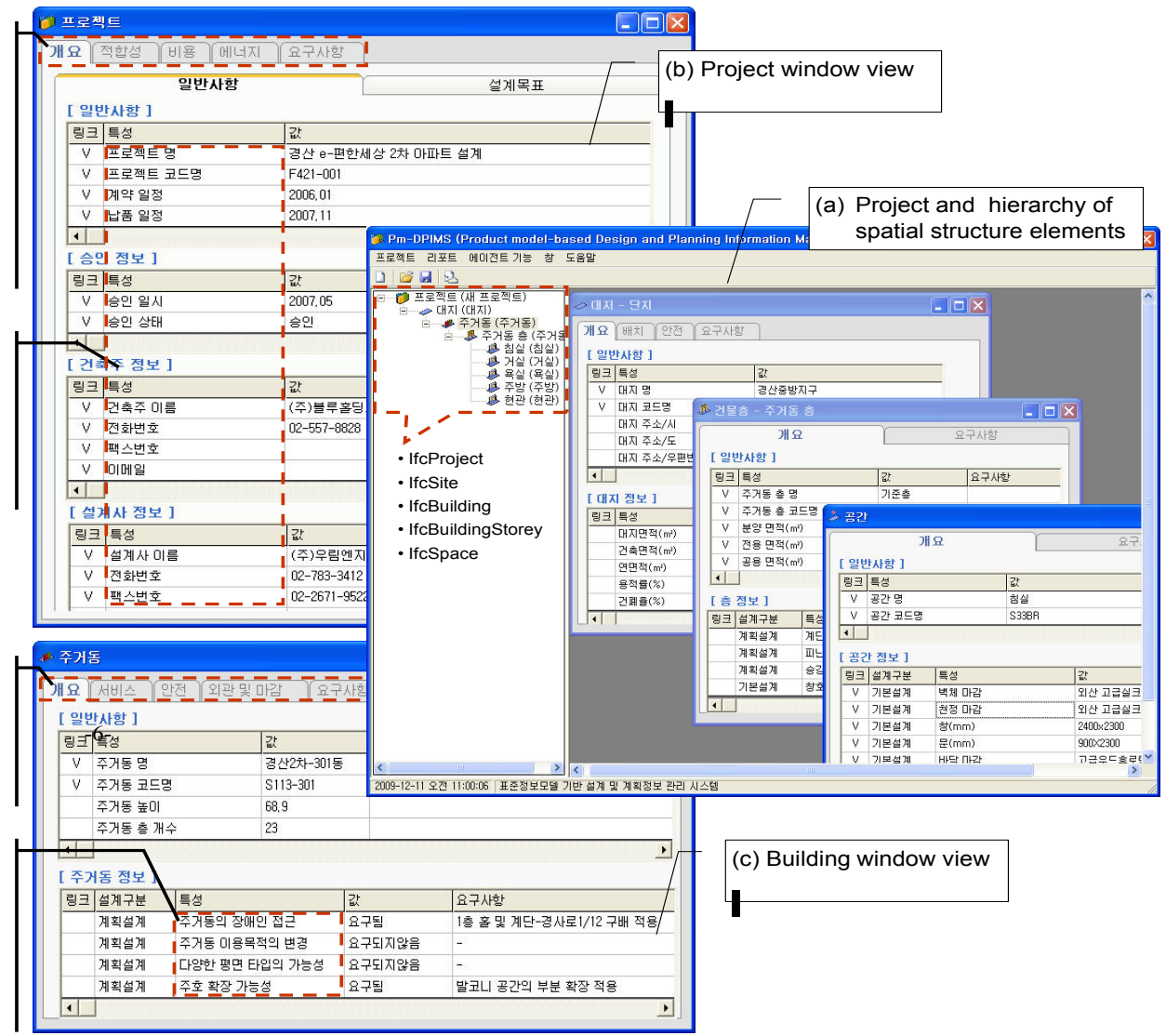

Figure 2. Input interfaces for planning information are mapped into the IFC extension model; the newly defined properties are HandicapCirculationAccess, BuildingUseChange, MultiPlanPossibility, and SpaceExtensionPossibility added in Pset_ BuildingCommon. As explained above, the template mdb not only provides the pre-defined planning items required to input the planning information but also enables the generation of userdefined planning items and the input of planning information to them.

\subsubsection{Linkage and Addition of Planning Information into an IFC Design Model}

As mentioned in the Introduction, Pm-DPIMS was developed to solve problems that result from the failure to manage and use planning information. The method allows planning information to be shared, managed, and used continuously in an IFC standard form with the design model during the design process. From a practical point of view, the planning information and design model exist separately during the design process, and the design model is

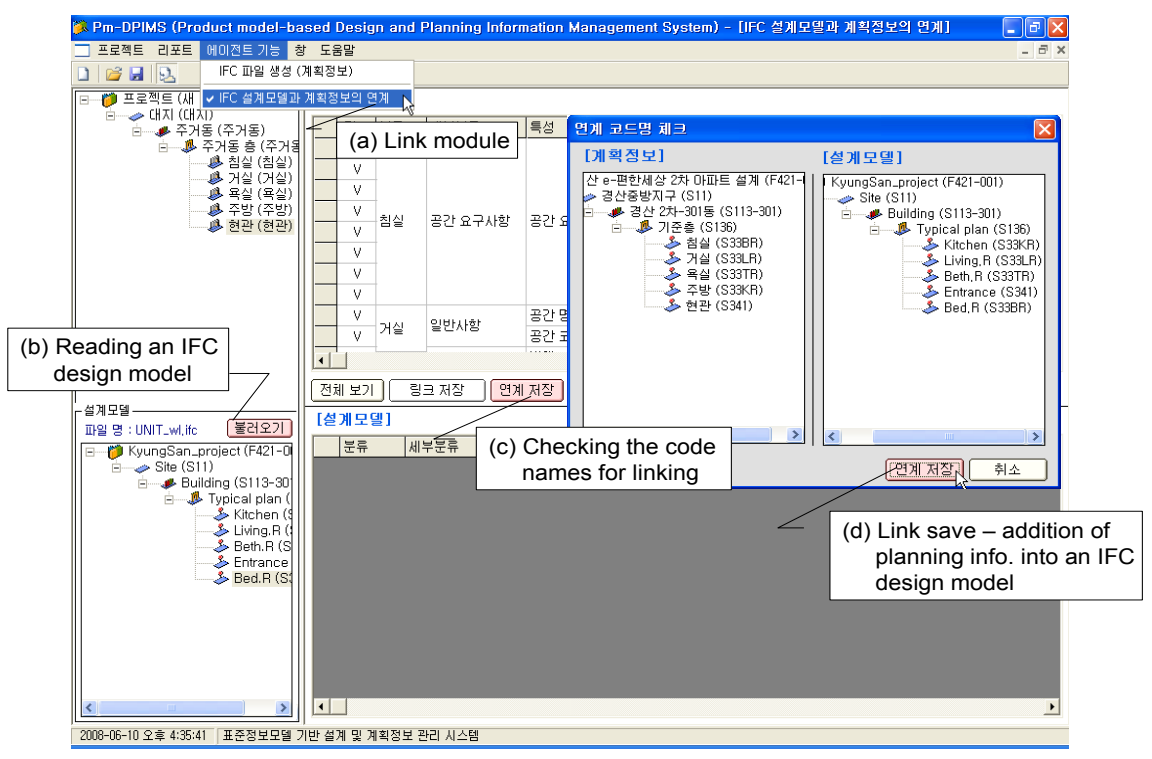

Figure 3. Link interfaces 
transmitted only to designers or engineers of other design offices with professional expertise in each design phase. However, other designers or engineers cannot easily understand the intentions and rationales of previous design work, as this phase does not involve cooperation among participants; therefore, before transmitting design products, the planning information needs to be added semantically into the design model to explain the intentions and rationales of the current design work, which result from the decisions of participants during the design phase. In this case, the planning information and design model should be applied with the same code name system to each project and spatial structure element in the design. Classified codes are applied using the Korean construction information classified system (MLTM, 2009). This classified system has been recognized and used as a construction standard that deals with classified codes and hierarchies of facilities, spaces, elements, works, and resources. The classified codes in this research focused on apartment buildings, and the codes were applied and extended according to their respective projects and spatial structure elements, as shown in an interface (c) of Figure 3. The project (F421-001) is composed of one or many sites; each site (S11) is composed of one or many buildings; each building (S113-301) is composed of one or many stories; and each storey (S136) is composed of one or many spaces. Therefore, the classified codes for projects and spatial structure elements should be inputted according to the classified system when the planning information and design model are generated. As mentioned above, the application of classified codes is meant to connect and add the planning information about the project and each spatial structure element in an IFC design model by using the link module of PmDPIMS. The link module provides functions such as reading an IFC design model instance file (b), checking code names (c), and linking and adding the planning information within the IFC design model instance file (d), as shown in Figure 3. A check of code names (c) is executed to examine whether the code names are the same between the planning information and the IFC design model; this is executed to prevent any inappropriate addition of planning information to the project and spatial structure elements existing within the IFC design model. If all codes do not exist equally, the module (c) automatically shows an error message that can detect and mark any inconsistent or illogical information items, and if all codes exist equally, the IFC design model instance file is regenerated with the planning information via the link and save module (d).

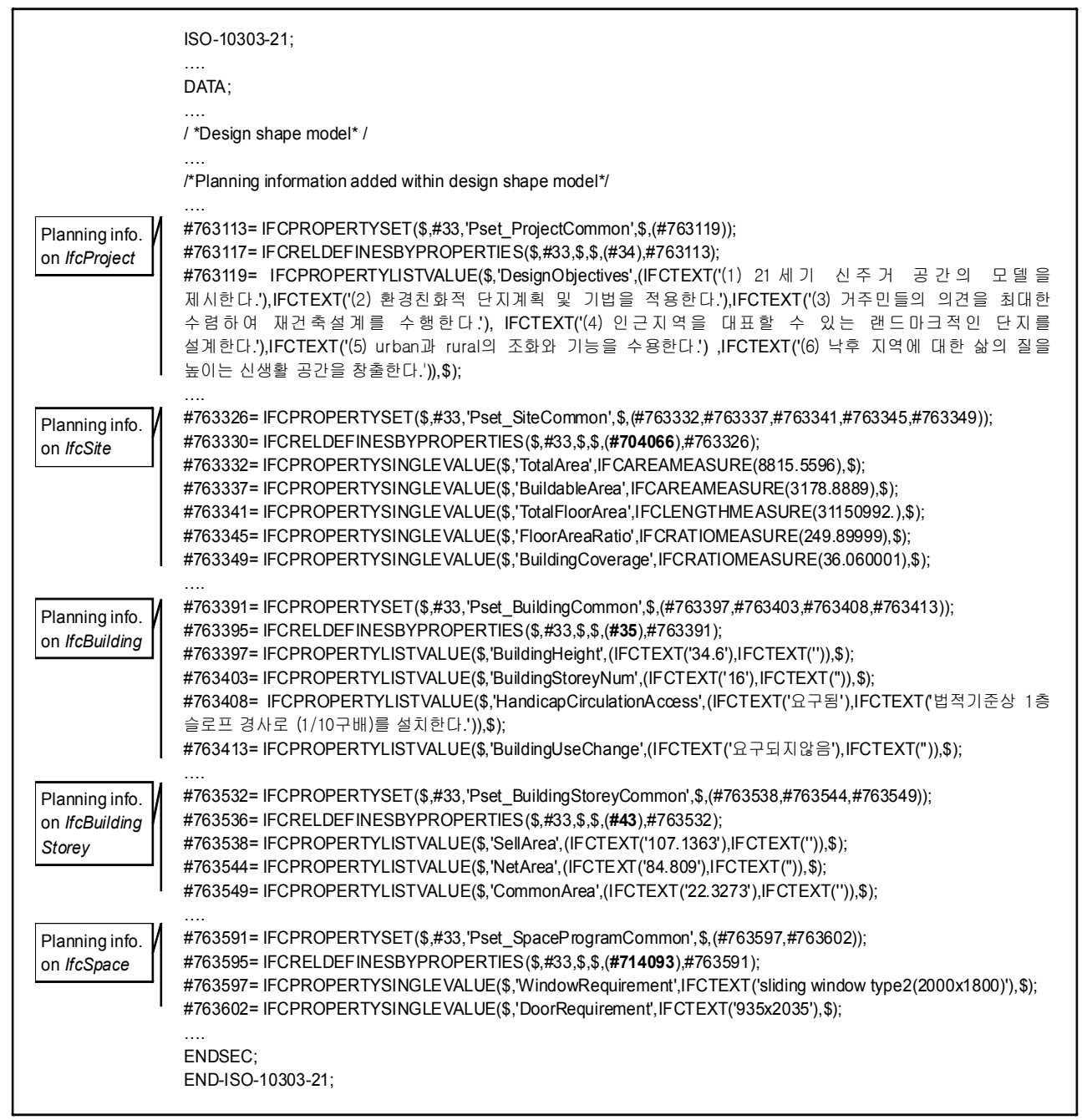

Figure 4. Parts of the IFC design model instance file with planning information 


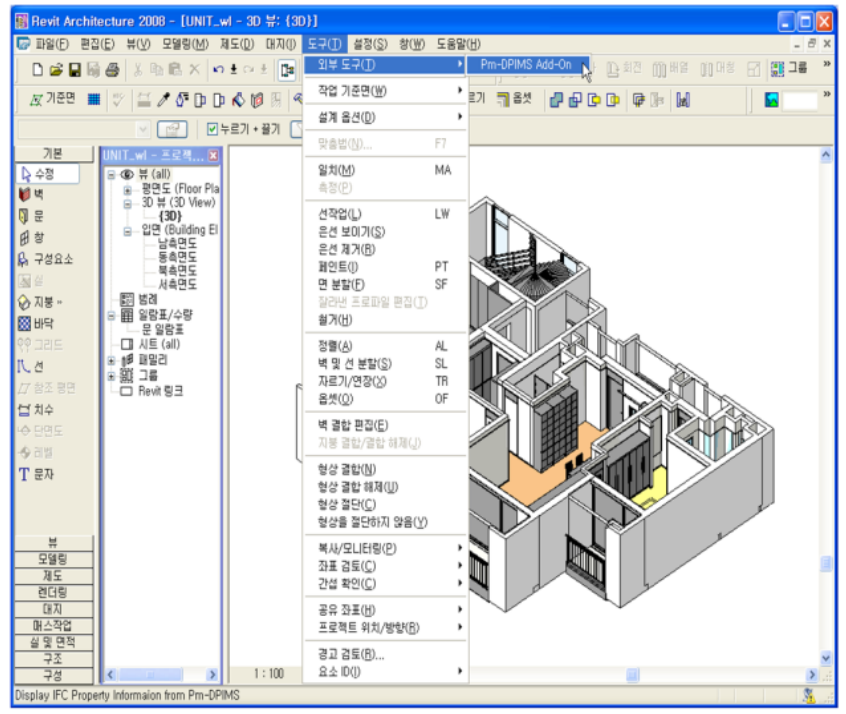

(a) Executing the Revit add-on of Pm-DPIMS for tracing the planning information

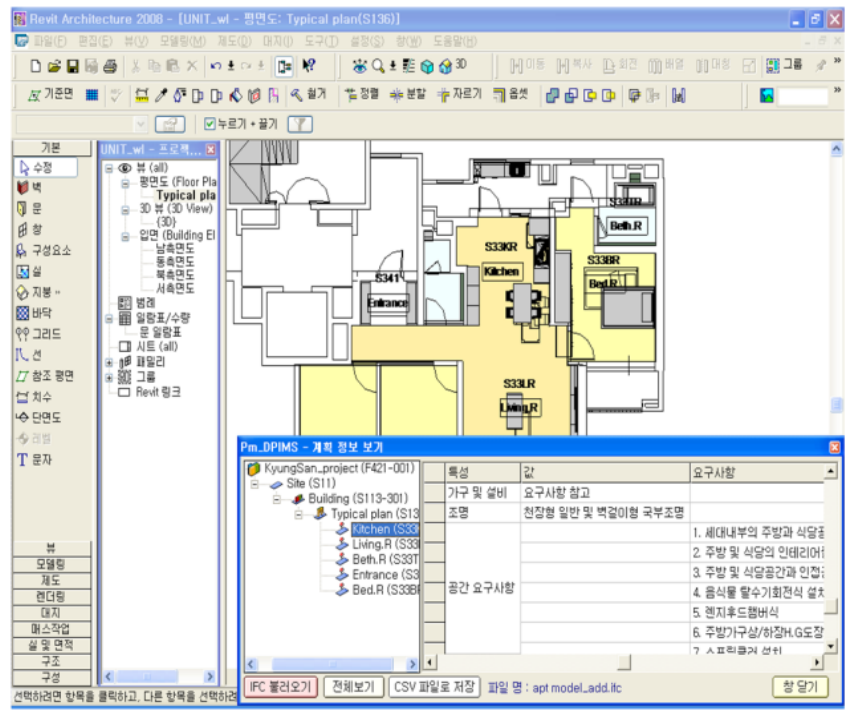

(b) The tracing of the planning information existing within IFC design model

Figure 5. Planning information traced by the Revit add-on of Pm-DPIMS

As a result, Figure 4 shows parts of the IFC design model instance file (encoded in EXPRESS, ISO10303 Part 21 format) (ISO, 2002) with planning information generated by the link module. The IFC instance file was generated by the IFC conversion algorithm with the link module; the algorithm supports the generation of IFC instance files according to the representation structures of the IFC schema after the link process. The design model includes geometric and style information, which is required to represent the project and spatial structure element objects such as IfcProject, IfcSite, IfcBuilding, IfcBuildingStorey, and IfcSpace. All planning information is connected to the project and spatial structure elements existing within the design model by object reference numbers. For instance, the IfcRelDefinesByProperties (\#763395) connects the IfcBuilding (\#35) and the IfcPropertySet (\#763391), and the IfcPropertySet is defined as a set of semantic descriptions (planning information) for the IfcBuilding. (See Ref. Seo and Kim, 2009 , for more details on verifying the IFC extension.)

\subsubsection{Tracing of Design Intentions and Rationales}

The Revit add-on module of Pm-DPIMS provides a tracing function that can extract planning information from an IFC design model, as shown in Figure 5. The tracing process is begun by opening an IFC design model instance file, and is executed by selecting the Pm-DPIMS add-on command in the tool menu (a). After this process, the planning information in the project and spatial structure elements of the IFC design model instance file are traced into a dialog screen interface (b). If the planning information or the IFC design model needs to be changed, they can be separately modified in each Pm-DPIMS and Revit ${ }^{\oplus}$ modeling tool. Moreover, after each design phase is completed, the IFC design model instance file with planning information can be regenerated by using the PmDPIMS, and the instance file is then transmitted into the design phases along with any work of designers or engineers in other design offices. In such cases, a separate and integrated method was used in the implementation of Pm-DPIMS by conducting interviews with practitioners (designers and engineers) in charge of multi-disciplinary design projects. This makes it possible to interpret the intentions and rationales of previous projects, because the planning information can be continuously shared during the design process. This approach can also improve productivity and efficiency in three-dimensional (3D) design projects.

\section{PROPOSED METHOD}

\subsection{Overall Process}

The Pm-DPIMS aims to manage and use planning information and design models in design applications, and to enhance cooperation among participants in the apartment building design projects. In this sense, the working method needs to be established to support the management and use of planning information and design models generated by Pm-DPIMS. Figure 6 shows an overall working method for managing and using design information in an IFC standard environment. This method focuses on the management and use of design information with the use of PmDPIMS and Revit tool. The Revit tool is selected as it is used mainly in BIM-based apartment building design projects and three design offices that execute the case application and evaluation in this research. In the schematic design phase (A2), the planning information $\mathrm{mdb}$ and the design model draft rvt file are generated from planning information defined roughly in the initial phase (A1). The products in the schematic design phase are extended and elaborated in the design development phase (A3). An IFC design model solution that includes planning information is also generated to manage and use the planning information in the construction document phase (A4); the planning information in the IFC design model is then used to communicate the intentions and rationales of previous work executed in the design process by using the Revit ${ }^{\circ}$ add-on of Pm-DPIMS. In addition, the proposed process was reviewed and defined through discussions with participants in charge of three design offices (will apply and evaluate this research) executing apartment building design projects. 


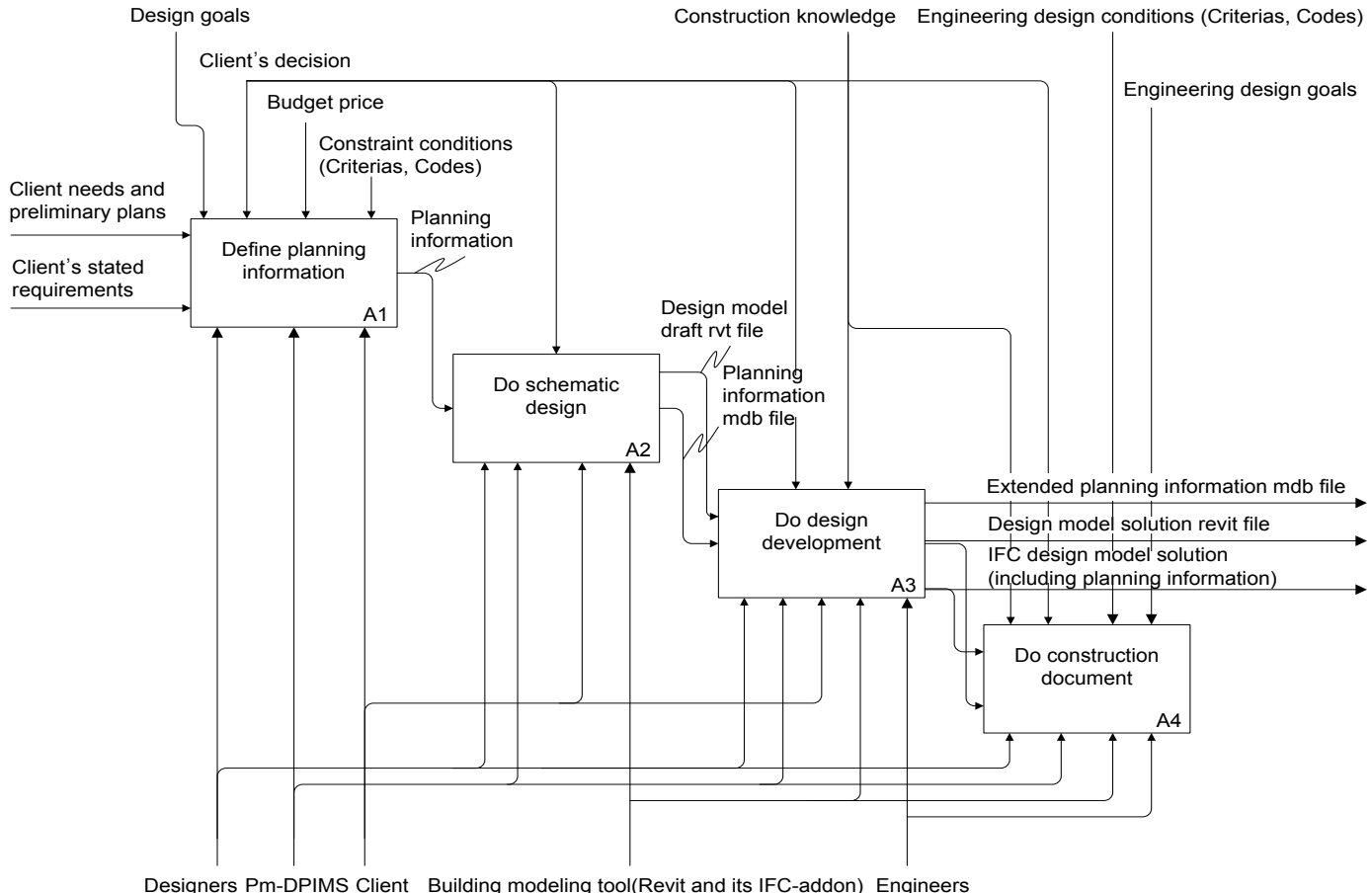

Figure 6. Diagram of an overall process

\subsection{Schematic Design}

In the schematic design phase, a design model is generated according to initially defined planning information lists, such as design goals, requirements, and constraint conditions, among others. Planning information is reported as either a paper document or an Excel $^{\circ}$ spread sheet using the report module of
Pm-DPIMS (A22), as shown in Figure 7. A design model draft is generated by the designers using the Revit tool according to the reported planning information (A23). After these steps are performed, the planning information and the design model draft are modified through discussions among participants during the schematic design phase (A24). In this case, the planning

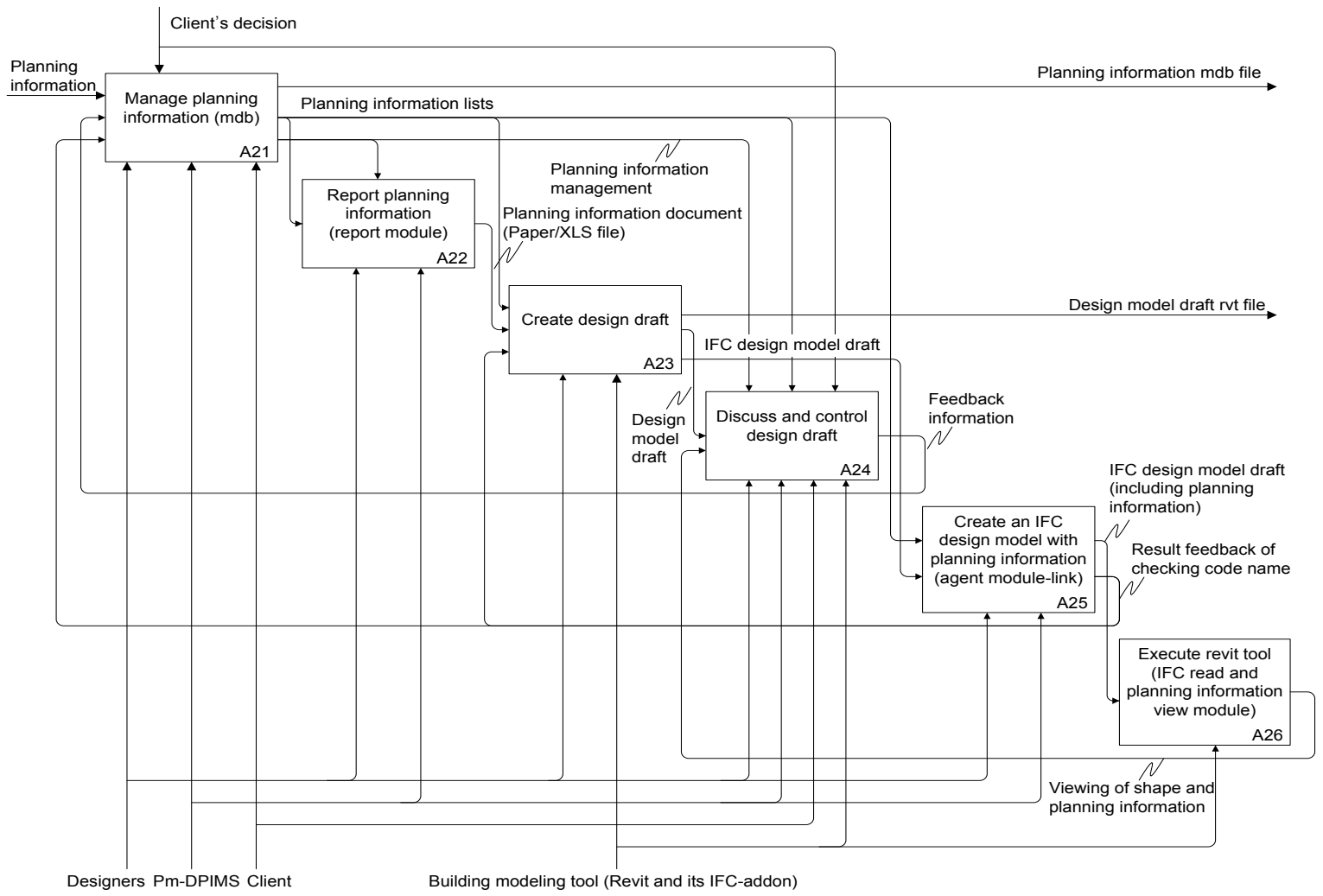

Figure 7. Schematic design diagram 
information may be connected and added to the design model draft, since it is used in the form of semantic descriptions, such as intentions and rationales, to generate a draft of the design model during either the design evaluation or the next phase. In the case of entering the planning information into the Pm-DPIMS and generating the design model draft in the Revit tool, the same classified code names are applied to the project and spatial structure elements. The link module of Pm-DPIMS is then executed to link and add the planning information within the IFC design model draft generated by the IFC add-on module of the Revit tool (A25). The IFC design model draft is subsequently visualized by the IFC import module of the Revit tool. In this case, the Revit add-on module of Pm-DPIMS is used to support the tracing and viewing of planning information that exists within the IFC design model draft (A26). General project information and semantic descriptions connected to design objects (project and spatial structure elements) are visualized in the Revit tool.

Figure 8 shows the process in the A25 activity of Figure 7 in detail. The work process is begun by reading an IFC design model draft in the Revit tool (A252). Next, if link saving is conducted (A253), then the code names of the project and spatial structure elements within the IFC design model draft and the planning information $\mathrm{mdb}$ are extracted into each list with tree structures to check the code names (A254), as shown in Figure 3. After an automatic check, the code names in either the planning information lists or the IFC design model draft can be modified according to the results of A254 activity. If the results are exact, all of the planning information is automatically linked and added to the project and spatial structure elements within the IFC design model draft, and the IFC design model draft is then regenerated in the IFC standard format using the IFC conversion module of Pm-DPIMS (A255).

\subsection{Design Development}

Through the cooperation of participants during the design project, planning information and the design model are extended in detail in the design development phase. The design development phase involves the same method as that used for the schematic design phase (Figures 7 and 8), but requires detailed planning information and an architectural design model to support the construction document phase that generates various design products, such as structure, building services (heating, ventilation, and air conditioning), and the landscape design model. The design products during the construction document phase are based fundamentally on a completed design model generated in the design development phase. Therefore, an extended planning information mdb, a design model solution rvt, and an IFC design model solution file are generated in this phase, and these files are used during the construction document phase to communicate the intentions and rationales of design projects formulated during the design development phase.

\subsection{Construction Document}

The construction document phase refers to the process of generating results from the design development phase; the results are used to create detailed and diverse design products required for constructing apartment houses. In this case, planning information can be accessed by tracing and viewing in the Revit add-on module of Pm-DPIMS. The module may also be used from the schematic design phase to the construction document phase according to its purpose. This means that the semantic descriptions (planning information) within an IFC design model can be continuously managed and used, as many design modeling tools support the IFC standard format.

\section{EVALUATION}

\subsection{Evaluation Process}

A proposed working method using Pm-DPIMS (including its Revit add-on) was evaluated to determine whether it is superior to current methods used in design offices in terms of the management

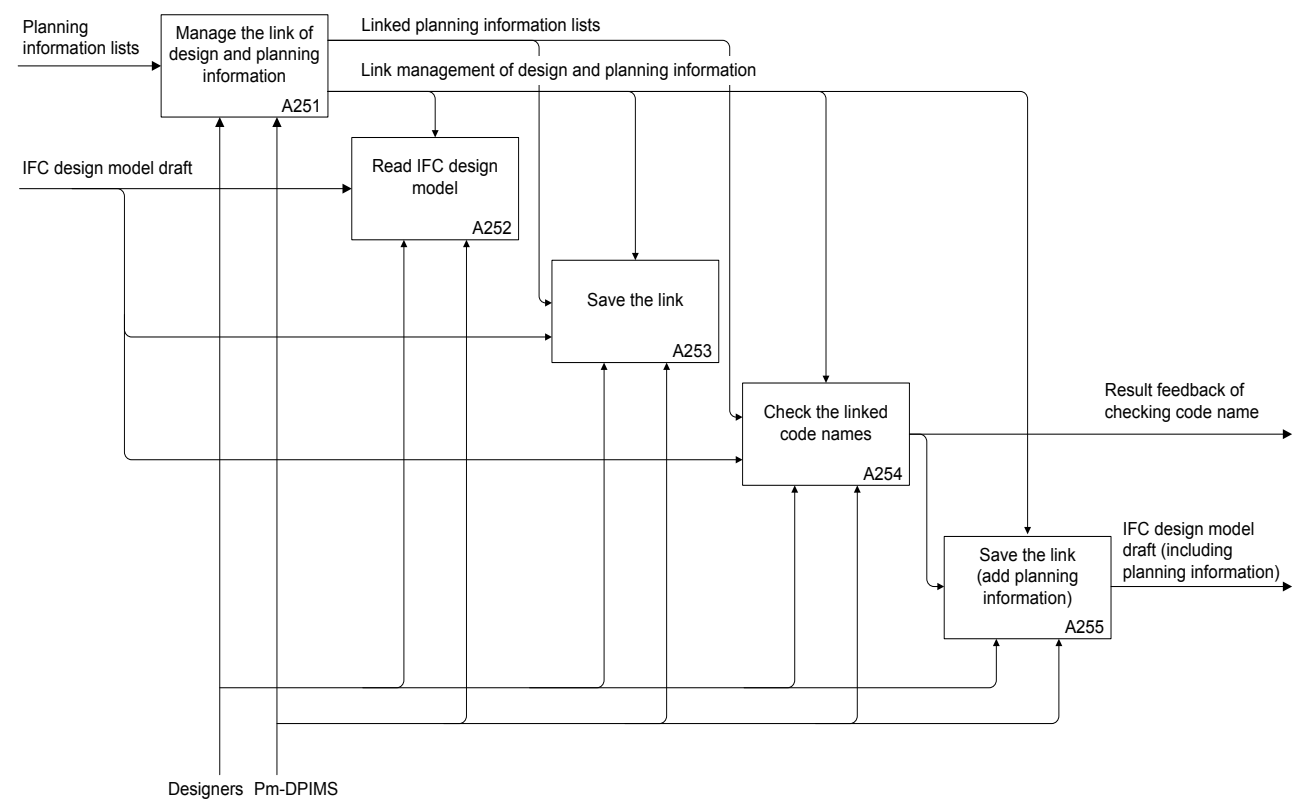

Figure 8. Link diagram of an IFC design model with planning information 
and use of design information. The evaluation was executed within the existing design projects for the apartment house, with participants in charge from three design offices (refer to Figure 9). To apply and evaluate the proposed method, documents (proposed method, user guide, and evaluation questionnaire) and PmDPIMS were provided for the participants in each design office; the questionnaire here mainly follows the evaluation criteria that are described in Section 4.2. Subsequently, participants applied and evaluated the proposed method with the use of Pm-DPIMS. After that, responses to questionnaire and digital photos to internal evaluation discussion were collected from each design office, and the results were reported in order to evaluate the usefulness and efficiency of the proposed method.

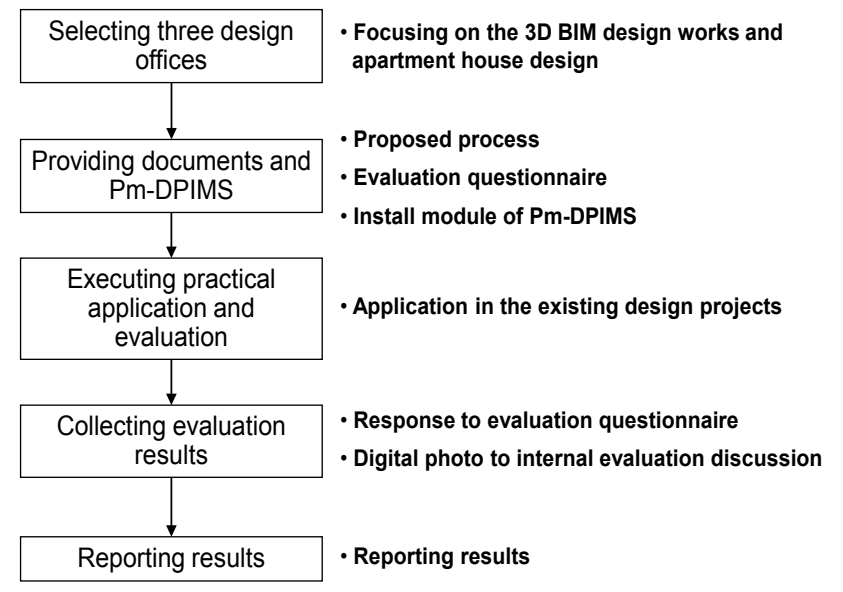

Figure 9. An overall evaluation process

\subsection{Evaluation Criteria and Method}

To demonstrate the usefulness and efficiency of the proposed method, an Analytic Hierarchy Process (AHP) was applied as one of the decision-making methods in this research (Roy, 1996). The AHP is used as a decision-making method that collects the knowledge, experience, and judgment of evaluators who can compare alternatives, and assesses the relative importance or preferences of various evaluation criteria to determine the best options. To apply the AHP, the evaluation criteria were derived from the main problems that arise in design projects as mentioned in the Introduction. To validate the evaluation criteria, also, there were reviewed by participants with professional knowledge at three design offices. The criteria were main factors such as thee communication of information (a), the use of planning information (b), the interoperability of planning information (c), and the collection and management of planning information (d), as shown in Table 1.

The evaluation method includes developing a questionnaire form, collecting responses to the questionnaire, calculating the importance of criteria and evaluation scores, and evaluating the overall scores in light of their assigned weights. The relative importance scores among the criteria were used as the weights of the evaluation. The importance of each evaluation criterion was rated on a scale from 1 to 9 as proposed by Saaty, and evaluation scores used 5 point criteria $(5=$ very high, $4=$ high, $3=$ normal, 2 $=$ low, $1=$ very low). The evaluation was executed through internal discussions after the proposed method was applied in each design office during approximately one month. Figure 10 shows the internal discussion on evaluation executed in one of three design offices. This process was executed equally even in other design offices.

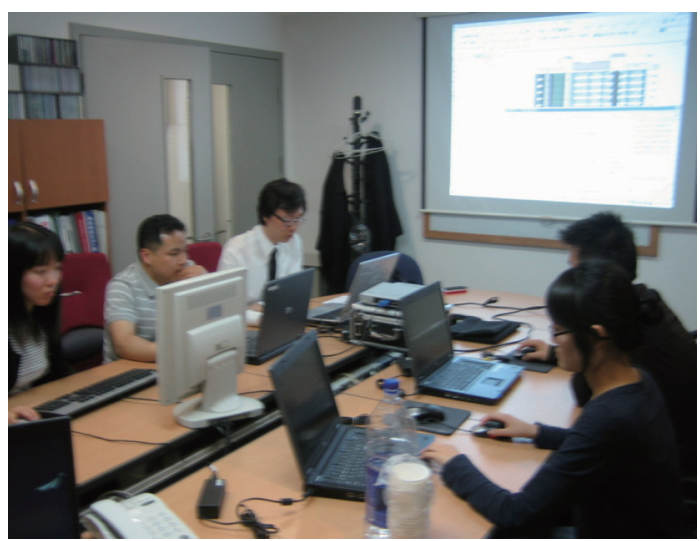

Figure10. Discussion on evaluation

\subsection{Evaluation Results}

The results were tabulated after collecting responses to the questionnaire, as shown in Table 1. After collecting responses to questionnaire from three design offices (company $\mathrm{A}, \mathrm{B}$, and $\mathrm{C}$ ), the relative importance of each criterion was defined and calculated as a weighted value for each total evaluation score to compare the proposed method with other current methods.

All participants agreed that the proposed method was an overall improvement in comparison with other current methods. In particular, the interoperability of planning information was found to be most important among evaluation criteria. The use of planning information was likewise shown to be highly important. These results indicate that the current customs and practices of design projects still make it difficult to collect and use planning information during the design process, and that various kinds of design information are not fully interoperable for use with design tools. In other words, participants in the case studies currently cannot explore a standard-based environment from this perspective that is continuously managed and used by sharing and exchanging design information, and such an environment is not incorporated into design tools used in current design projects. Consequently, as shown in design offices $\mathrm{A}, \mathrm{B}$, and $\mathrm{C}$, the proposed method can be more beneficial and effective than current methods, as evident from the total evaluation score. This result also means that the method using Pm-DPIMS and its Revit add-on can be used to enhance cooperation and adjustment in design projects.

\subsection{Discussion}

The proposed method focused on the management and use of design information using application tools such as Pm-DPIMS, its Revit add-on module, and Revit". As a result, the method could be used to improve the communication among participants with merits gained from BIM design methods and to enhance the efficiency of design works, as shown in Table 1.

From an IFC perspective, the result of this research has an issue on the sharing and exchange of planning information between Revit and other BIM modeling tools. Currently, main BIM modeling 
Table 1. Total evaluation results

\begin{tabular}{|c|c|c|c|c|c|c|c|c|c|c|c|c|c|c|c|}
\hline \multirow{3}{*}{ Criteria } & \multirow{2}{*}{\multicolumn{3}{|c|}{ Weights }} & \multicolumn{6}{|c|}{ Evaluation score } & \multicolumn{6}{|c|}{ Total evaluation score } \\
\hline & & & & \multicolumn{3}{|c|}{ Current work } & \multicolumn{3}{|c|}{ Proposed work } & \multicolumn{3}{|c|}{ Current work } & \multicolumn{3}{|c|}{ Proposed work } \\
\hline & A & B & $\mathrm{C}$ & A & B & $\mathrm{C}$ & A & B & $\mathrm{C}$ & A & B & $\mathrm{C}$ & A & B & $\mathrm{C}$ \\
\hline $\mathrm{a}$ & 0.08 & 0.05 & 0.2 & 1 & 2 & 3 & 3 & 3 & 4 & 0.08 & 0.1 & 0.6 & 0.24 & 0.15 & 0.8 \\
\hline $\mathrm{b}$ & 0.25 & 0.21 & 0.24 & 2 & 2 & 2 & 4 & 5 & 5 & 0.5 & 0.42 & 0.48 & 1 & 1.05 & 1.2 \\
\hline $\mathrm{c}$ & 0.45 & 0.54 & 0.4 & 1 & 3 & 2 & 4 & 4 & 4 & 0.45 & 1.62 & 0.8 & 1.8 & 2.16 & 1.6 \\
\hline d & 0.22 & 0.2 & 0.16 & 1 & 1 & 2 & 3 & 5 & 4 & 0.22 & 0.2 & 0.32 & 0.66 & 1 & 0.64 \\
\hline $\begin{array}{l}\text { Total } \\
\text { score }\end{array}$ & 1 & 1 & 1 & & & & & & & 1.25 & 2.34 & 2.2 & 3.7 & 4.36 & 4.24 \\
\hline
\end{tabular}

tools include IFC-compliant capability. However, problem on data interoperability among BIM modeling tools still remains as one of critical issues from industrial need, as the tools have not the data accessibility with the same interpretation during IFC export and import process. In this context, this research supports the interoperability of planning information between Pm-DPIMS and Revit" tool (including its add-on). Although planning information is not shared between Revit and other modeling tools, the problem of interoperability originates from differences in versions being used, even in the same application tool. For instance, the rvt file format generated by the latest version of Revit cannot be read by the previous version. However, the use of Pm-DPIMS with IFC schema and its extension model (Psets and their properties) enables the management and use of planning information regardless of versions of the Revit tool. In addition, The IFC schema with the extension model ensures the quality of IFC-compliant BIM modeling tools. These tools require only the implementation of an interface to trace the planning information within an IFC design model instance file with planning information, as an example of the Revit add-on of Pm-DPIMS. If CAD vendors execute the robust implementation of IFC specification and then this interface such as Revit add-on is implemented in other BIM tools, the planning information will be shared and exchanged continuously among IFC-compliant BIM modeling tools, with collaboration and adjustment of practitioners carrying out multi-disciplinary tasks in a design project.

\section{CONCLUSIONS}

Traditional design projects entail long and repetitive review processes because they fail to efficiently manage and use design information, and lack cooperation and compromise among partici pants.

This research attempts to collect, manage, and use design information input among participants of design projects in an IFC standard form that can be managed and used to communicate the intentions and rationales of previous works in the design process. The proposed method demonstrated the efficiency and usability of Pm-DPIMS and its Revit add-on for use with planning information in support of design work activities. It can also be used as an alternative method to improve communication and work efficiency by capturing and reusing interoperable and semanticsrich information with building design objects.

Further research efforts will be made to improve the performance of Pm-DPIMS, to propose the method to be most efficient with its use, and to implement in BIM tools other than Revit, thus ensuring greater consistency in the communication of design information in design projects.

\section{REFERENCES}

Boddy, S., et al. (2007) "Knowledge informed decision making in the building lifecycle: an application to the design of a water drainage system." Automation in Construction, 16, 596-606.

BuildingSMART. (2010) (http://www.buildingsmart.com/content/ buildingsmart_international) $<$ November 15, 2010> .

BuildingSMART. (2011) "IFC releases published by buildingSMART." (http://www.iai-tech.org/products/ifc_ specification/ifcreleases/summary) < January 10, 2011>.

Choi, Y., Yi, J., and Bae, J. (2006) "A study on selecting key factors of design management considering current situation of design process." Journal of the Architectural Institute of Korea, 22(10), 111-118.

Cooper, G., et al. (2005) "Tracking decision-making during architectural design." Journal of Information Technology in Construction, 10, 125-139.

Gallaher, M., et al. (2004) "Cost analysis of inadequate interoperability in the U.S." Technical Report, Capital Facilities Industry, National Institute of Standards and Technology.

Hitchcock, R. (1996) Improving life-cycle information management through documentation of project objectives and design rationale. PhD thesis, Dept. of Civil Engineering, University of California, Berkeley, USA.

Hong, S., and Song, S. (2002) "A study on the characteristics of communications during design process in large architectural firms." Journal of the Architectural Institute of Korea, 18(7), 35-42.

International Organization for Standardization (ISO). (2002) "Industrial automation systems and integration: Product data representation and exchange: Part 21: Implementation methods: Clear text encoding of the exchange structure." TC 184/SC 4, Geneva, Switzerland. 
Lawrence Berkeley National Laboratory (LBNL). (2009) "Design Intent Tool." (http://ateam.lbl.gov/DesignIntent/home.html) $<$ September 9, 2009>.

Ministry of Land, Transport and Maritime Affairs (MLTM). (2009) "Applying Standard of Construction Information Classification System." 2009-781.

Ozkaya, I., and Akin, O. (2007) "Tool support for computer-aided requirement traceability in architectural design: the case of DesignTrack." Automation in Construction, 16, 674-684.

Roy, B. (1996) Multicriteria methodology for decision aiding. Kluwer Academic Publishers, Boston.

Seo, J., and Kim, I. (2009) "Industry Foundation Classes-based approach for managing and using the design model and planning information in the architectural design." Journal of Asian Architecture and Building Engineering, 8(2), 431-438.

Shin, J., et al. (2006) "Introducing information-oriented work process modeling method for effective design management in design collaboration." Journal of the Architectural Institute of Korea, 22(8), 181-188.

Trelligence Co., Ltd. (2010) "Affinity overview." (http://www. trelligence.com/affinity_overview.php) $<$ June 27, 2010>.

U.S. Army Corps of Engineers. (2010) "Facility Compuser." (https:// ff.cecer.army.mil/fc) $<$ July $24,2010>$.

VTT Technical Research Centre of Finland. (2009) "Requirements management - EcoProP." (http://cic.vtt.fi/eco/ecoprop/english/ EcoProp_brochure.pdf) <July 15. 2009>.

(Date of Submission : 2011.2.7) 